\title{
Celso Furtado: subdesenvolvimento e dependência tecnológica
}

\author{
Tatiane Ap.Viega Vargas* \\ Anielle Gonçalves de Oliveira**
}

\section{Resumo}

Furtado foi um economista brasileiro que dedicou sua vida acadêmica às questões do desenvolvimento. Preocupava-se com a criatividade dos pesquisadores latino-americanos em pensar os projetos desenvolvimentistas com um olhar atento aos fenômenos históricos e estruturais, que são elementos fundamentais de análises para o Brasil. O objetivo deste artigo é fazer uma releitura das obras Teoria Política do Desenvolvimento Econômico (1986) e $O$ Capitalismo Global (1998) escritas por Celso Furtado e em alguma medida comparar com os problemas apontados por ele e ainda não superados no Brasil. A metodologia utilizada foi a revisão bibliográfica das obras elencadas. Na primeira obra, Teoria Política do Desenvolvimento Econômico, especial atenção foi dada a quarta parte do livro, intitulada $O$ subdesenvolvimento. Parte-se de uma análise histórica do processo de desenvolvimento mundial, até chegar no subdesenvolvimento, finalizando com a análise da dependência tecnológica, onde as autoras fizeram uma breve relação com o comércio exterior brasileiro. $\mathrm{Na}$ segunda obra $O$ Capitalismo Global, Furtado situa o recém iniciado processo de globalização, chamando atenção para aumento da dependência das relações centro-periferia, e consequente ampliação das desigualdades sociais.

Palavras-chave: Celso Furtado, subdesenvolvimento, dependência.

\section{Celso Furtado: underdevelopment and technological dependence}

\begin{abstract}
Furtado was a Brazilian economist who dedicated his academic life to development issues. He was concerned with the creativity of Latin American researchers in thinking about development projects with an attentive eye to historical and structural phenomena, which are fundamental elements of analysis for Brazil. The purpose of this article is to review the works Teoria Politica do Desenvolvimento Econômico (1986) and O Capitalismo Global (1998) written by Celso Furtado and to some extent compare with the problems pointed out by him and not yet overcome in Brazil. The methodology used was a bibliographic review based on the listed works. In the first work, Teoria Política do Desenvolvimento Econômico, special attention was given to the fourth part of the book, entitled $O$ subdesenvolvimento. It starts with a historical analysis of the world development process, until it reaches underdevelopment, ending with the analysis of technological dependence, where the authors made a brief relationship with Brazilian foreign trade. In the second work $O$ Capitalismo Global, Furtado situates the recently initiated globalization process, calling attention to the increase in dependence on center-periphery relations and the consequent expansion of social inequalities.
\end{abstract}

Keywords: Celso Furtado, underdevelopment, dependency.

Classificação JEL: O1; O10

\footnotetext{
* Professora do Departamento de Economia da Fundação Universitária da Região de Blumenau (FURB). E-mail: tatianeviega@gmail.com

** Professora do Departamento de Economia do Centro Universitário para o Desenvolvimento do Alto Vale do Itajaí (UNIDAVI). E-mail: anielleg20@ unidavi.edu.br
} 


\section{Introdução}

Escrever sobre Celso Furtado poderia ser considerado uma tarefa de fácil realização, afinal, temos um acervo considerável que nos permite uma vasta fonte de referências. Mas pensar "sobre" e "com" Celso Furtado, definitivamente não é tarefa fácil, sua genialidade não permite que façamos ensaios superficiais, pelo contrário, nos coloca em situação de grande responsabilidade. Pois foi assim, com responsabilidade que Furtado pensou, escreveu e ousou sonhar o país. Um Brasil que poderia sim, superar as desigualdades, através de planejamento e de políticas públicas de enfrentamento da herança colonial, à qual em alguma medida ainda nos encontramos subjugados. Assim, cientes dessa responsabilidade, esse artigo teve como objetivo revisitar duas obras de Celso Furtado, quais sejam: Teoria Política do Desenvolvimento Econômico (1986) e O Capitalismo Global (1998), e através delas refletir sobre a produção e trocas contabilizadas na pauta do comércio internacional em 2019 e 2020.

Iniciamos descrevendo brevemente a vida acadêmica e política de Celso Furtado. Foi certamente um dos mais importantes economistas brasileiros, Paraibano, nascido em Pombal, em 26 de julho de 1920, segundo filho de uma família de oito irmãos. Seu pai foi advogado e sua mãe filha de donos de terras. Ainda aos 7 anos de idade mudou-se com sua família para a capital João Pessoa. Estudou no Liceu Paraibano e completou os estudos no Ginásio Pernambucano, no Recife. Aos 19 anos chega ao Rio de Janeiro, indo morar em pensões nos bairros do Flamengo e na Lapa (CENTRO CELSO FURTADO, 2020).

No Rio de Janeiro, Furtado cursou a faculdade de direito. Durante o curso prestou dois concursos na área pública e nos dois passou em primeiro lugar. Assumindo cargo em função pública essa temática passou a ocupar grande parte de sua pesquisa e ele começou a publicar textos neste universo. Quando terminava sua faculdade, no ano de 1944, o Brasil declarava guerra com as potências do eixo, foi quando Furtado partiu para a Itália. Quando voltou, em 1945, tinha algumas certezas: não queria ser advogado e seguiria seus estudos na área de ciências sociais. Ingressou no curso de doutorado em Economia na Universidade de Sorbonne, em Paris, onde defendeu a tese A economia colonial brasileira nos séculos XVI e XVII em 1948 (D’AGUIAR, 2020).

Aos 28 anos, retornando de Paris, Furtado vai para Santiago no Chile, trabalhar na recém fundada Comissão Econômica para a América Latina, a Cepal, quando inicia sua carreira como economista. Foram quase dez anos analisando e pensando a forma como as economias latino americanas se desenvolveram. Da Cepal, Celso parte em 1957, para Cambridge, UK, para lecionar. Volta ao Brasil em 1958 como diretor do BNDE para questões do Nordeste, foi onde 
dirigiu a Superintendência do Desenvolvimento do Nordeste (SUDENE). Participou da implementação de políticas para essa região durante três governos (Kubitschek, Quadros e Goulart). Por alguns meses (entre 1962 a 1963) foi o primeiro ministro do Planejamento do Brasil (D'AGUIAR, 2020).

Essa fase na carreira pública da vida de Celso Furtado foi encerrada em 1964 com o golpe militar, onde, exilado, sai da cena política brasileira e parte para a carreira acadêmica. Primeiro na Universidade de Yale; depois, (1965) volta à Paris, na Sorbonne, onde foi por 20 anos professor de economia do desenvolvimento e economia latinoamericana (D'AGUIAR, 2020).

Retorna ao Brasil novamente apenas em 1979. Lutou pela redemocratização brasileira ao lado de Ulysses Guimarães. Foi Ministro da Cultura (de 1986 a 1988). Suas reflexões como economistas versavam sobre desenvolvimento, subdesenvolvimento, estruturas dualistas. Furtado faleceu no Rio de Janeiro, em 20 de novembro de 2004 (D’AGUIAR, 2020).

A metodologia de pesquisa utilizada foi a revisão bibliográfica das duas obras, Teoria Política do Desenvolvimento Econômico (1986) e O Capitalismo Global (1998). Em suma o artigo está estruturado da seguinte maneira, (i) esta introdução, (ii) Obra: Teoria Política de Desenvolvimento Econômico, (iii) Obra: O Capitalismo Global, (iv) Breve histórico da balança comercial brasileira entre 2019 e 2020 e (v) Considerações finais.

\section{Obra: teoria política do desenvolvimento econômico}

Em seu livro "Teoria Política do Desenvolvimento Econômico", Furtado (1986) apresenta na primeira parte - dos capítulos 1 ao 6 - uma revisão de todas as teorias do desenvolvimento. Inicia pelos clássicos, explica o modelo de Marx, aborda os neoclássicos, Schumpeter, e por fim, a teoria keynesiana. Após esta, que ele chama de primeira parte - A teoria do desenvolvimento na ciência econômica - Furtado (1986) aborda, na segunda parte do livro o processo de desenvolvimento, utilizando um enfoque analítico. Na terceira parte, o autor continua analisando o processo de desenvolvimento, mas agora com um enfoque histórico.

Nesta pesquisa, especial atenção foi dada a quarta parte do livro, ao qual Furtado (1986) intitulou como - O subdesenvolvimento. Dos capítulos 13 até o 18 ele aborda os temas do subdesenvolvimento e relaciona questões históricas e estruturais da economia brasileira, bem como do desenvolvimento do capitalismo na economia-mundo. Fala de comércio exterior, industrialização, dualidade e dependência externa. E são estes temas que vêm ao encontro do 
objetivo deste artigo. A quinta parte - Política de desenvolvimento - é onde o autor consegue resumir ações de cunho político-prático. E também onde existe uma espécie de "organização das ideias" num sentido de fechamento, ou seja, uma conclusão geral da obra.

Para explicar subdesenvolvimento, faz-se necessário voltar ao processo histórico que levou ao patamar de desenvolvimento atual, os países conhecidos como "desenvolvidos". Furtado (1986) volta ao século XVIII, na Europa Ocidental, para analisar como se deu a propagação da revolução industrial. A primeira grande modificação trazida por este movimento foi dentro da própria Europa Ocidental, “[...] Neste caso o desenvolvimento assumiu a forma de desorganização da economia artesanal pré-capitalista e de progressiva absorção dos fatores liberados, a um nível mais alto de produtividade" (FURTADO, 1986, p.187). Nesta fase, até certo ponto a oferta de mão-de-obra era totalmente elástica, porém aos poucos, com o avanço da industrialização essa mão-de-obra tende a esgotar-se. Assim, o papel do progresso técnico assume um papel fundamental, já que o fator capital teria de combinar a falta de mão-de-obra com aumento de produção.

Em um segundo momento deste mesmo processo histórico, Furtado (1986) assinala que houve um deslocamento da economia industrial europeia "[...] para além de suas fronteiras de mão-de-obra, capital e técnica, onde quer que houvesse terras ainda desocupadas e de características similares às da própria Europa” (FURTADO, 1986, p. 188). Aqui é importante destacar países como Austrália e Estados Unidos, que receberam muitos destes emigrantes que levavam as técnicas e hábitos de consumo europeus em suas bagagens. Eram formadas "colônias" de emigrantes que se estabeleciam onde houvesse uma base ampla de recursos naturais, o que lhes propiciou, desde o início, elevados índices de vida, assim como tinham nos países europeus.

A terceira linha de expansão desta economia industrial foi no sentido de ocupar as regiões que já estavam em funcionamento, porém onde existiam sistemas considerados pelos europeus como "de natureza pré-capitalistas". Furtado (1986) afirma que este contato se deu de maneira diferenciada nos diferentes lugares. Em alguns limitou-se a abertura de novas linhas de comércio; outros o desejo de fomentar a produção de matérias-primas. Porém o autor é enfático ao colocar que "[...] a resultante foi quase sempre a criação de estruturas dualistas, uma parte das quais tendia a organizar-se à base da maximização do lucro e da adoção de formas modernas de consumo, conservando-se a outra parte dentro de formas pré-capitalistas de produção" (FURTADO, 1986, p.188). Portanto, o subdesenvolvimento não é uma fase ou etapa do desenvolvimento, mas sim um processo histórico autônomo, e também que esta estrutura dualista prevalece até hoje nestes espaços que, assim foram colonizados. 
Francisco de Oliveira, na obra Crítica à Razão Dualista: o ornitorrinco, aborda a estrutura dualista da economia brasileira. $\mathrm{O}$ autor, também, dedicou sua vida acadêmica aos estudos da forma específica com que o capitalismo se desenvolveu na estrutura brasileira. Em trecho desta obra, ele ressalta que,

\begin{abstract}
Ao enfatizar o aspecto da dependência - a conhecida relação centro-periferia -, os teóricos do "modo de produção subdesenvolvido" quase deixaram de tratar os aspectos internos das estruturas de dominação que conformam as estruturas de acumulação próprias de países como Brasil: toda a questão do desenvolvimento foi vista pelo ângulo das relações externas, e o problema transformou-se assim em uma oposição entre nações, passando despercebido o fato de que, antes de oposição entre nações, o desenvolvimento ou o crescimento é um problema que diz respeito a oposição entre classes sociais internas (OLIVEIRA, 2003, p. 33).
\end{abstract}

Com o intuito de reforçar a relevância desta forma de desenvolvimento - o subdesenvolvimento - na economia brasileira, Oliveira (2003) nos mostra em suas obras que a estrutura interna da economia brasileira e as relações estabelecidas entre as classes, é uma categoria de análise que precisa ser considerada. As relações de dependência externa, não são as únicas condicionantes da situação de desigualdade social existentes, até hoje em nosso país. Apesar de ser este o foco de análise desta pesquisa, fica claro que as autoras consideram o processo de estrutura interna relevante para que a manutenção e inclusive ampliação do quadro de desigualdades sociais brasileiros seja um dos principais problemas a serem enfrentados.

Segundo Furtado (1986) a teoria clássica do comércio internacional, que foi iniciada por Adam Smith e David Ricardo, deu continuidade por ressaltar que as trocas internacionais são mais vantajosas para todas as economias. Para os clássicos, o protecionismo dificulta o comércio externo e faz com que a produtividade na economia global decaia. A teoria neoclássica, quando trata do intercâmbio das mercadorias, afirma que trocar mercadorias é o mesmo que trocar fatores de produção. Essas trocas fariam com que aumentasse o preço dos fatores abundantes, e reduzisse o preço dos fatores escassos, pela lei da oferta e demanda.

\footnotetext{
O estudo dos fatores responsáveis pela perda de dinamismo da procura internacional de produtos primários, abriu a porta a uma crítica em profundidade da teoria tradicional do comércio internacional. Ao contrário do que se infere desta última, o intercâmbio externo não conduziu a uma igualização na remuneração dos fatores. Pelo contrário: ele tem operado no sentido de possibilitar a concentração da renda em favor dos países industrializados, mediante a deterioração a longo prazo dos termos do intercâmbio dos países especializados na exportação de matérias-primas (FURTADO, 1986, p. 228)
}

Este trecho do autor é bem claro ao mostrar a crítica feita por Furtado, e pelos demais economistas da CEPAL - Comissão Econômica para América Latina e o Caribe, à teoria clássica do comércio internacional. Um dos mais respeitados economistas da Cepal, o argentino 
Raul Prebisch fez um estudo que demonstrou a perda das vantagens comparativas ao longo dos anos, em detrimento dos países subdesenvolvidos. Neste ponto, faz sentido adentrarmos na segunda obra analisada neste texto, onde a análise sobre a crítica à teoria clássica fica mais evidente.

\section{Obra: o capitalismo global}

Na obra O Capitalismo Global, Furtado (1998) coloca que a partir dos anos 1930 o modelo agrário exportador começa a ser questionado no Brasil. Para o autor, o agrarismo era a causa do atraso no desenvolvimento brasileiro. Na época, mais de $90 \%$ das exportações nacionais eram produtos primários agrícolas. "Não que nosso país fosse totalmente destituído de indústrias. O que não havia era sistema industrial capaz de autogerar seu dinamismo" (FURTADO, 1998, p. 17).

É neste ponto que o autor chama a atenção, pela primeira vez nesta obra - O Capitalismo Global - para a questão da dependência tecnológica: "O problema não se limitava a depender da importação de tecnologia e de equipamentos para crescer, e sim dispor de uma classe dirigente capaz de formular um projeto de transformação do país" (FURTADO, 1998, p. 17). Furtado (1998) percebe que a classe dominante teria de mudar para que um projeto de desenvolvimentismo no Brasil pudesse acontecer, e ele acreditou que a classe industrial nascente poderia assumir esse papel.

Em meio a este cenário, um trabalho de Raul Prebisch intitulado: "Manifesto LatinoAmericano", traduzido por Furtado, foi publicado na Revista Brasileira de Economia. Essas ideias deram base ao pensamento estruturalista e, segundo Bielchowsky (2020, p. 4) estas são "palavras que apenas situavam o significado da industrialização no contexto histórico por que passava a América Latina”.

Este manifesto foi importante pois deu subsídio teórico para que fossem implementadas mudanças no direcionamento da política brasileira rumo à industrialização. Furtado (1998) coloca como importantes alavancas para esse processo a prolongada depressão dos anos 30 e os transtornos trazidos ao comércio em virtude da guerra. "Em síntese, as possibilidades da atividade industrial eram tão grandes, no Brasil, que mesmo medidas precárias nessa direção produziram resultados apreciáveis" (FURTADO, 1998, p. 19-20).

Furtado (1998) faz uma reflexão acerca do processo histórico de formação econômica do mundo moderno. Nesta reflexão o autor conclui que, em resumo, dois processos foram os responsáveis pelo dinamismo da economia capitalista nos países centrais: a inovação técnica e 
a expansão do mercado. "O peso do primeiro destes fatores (a inovação técnica), depende da ação dos empresários em seus esforços de maximização de lucros, ao passo que o peso do segundo, (a expansão do mercado), reflete a pressão das forças sociais que lutam pela elevação de seus salários" (FURTADO, 1998, p. 29). Desta forma, ainda que reflita na realidade econômica, Furtado deixa o comércio internacional, principalmente as exportações, em segundo plano, com contribuições apenas subsidiárias.

Porém, quando o autor começa a analisar o processo de globalização que se iniciava, ele alerta para uma possível mudança de quadro. Afirma que com a globalização das empresas, estas acabam "escapando" da ação reguladora do Estado, se apoiando mais nos mercados externos para crescerem, o que pode acontecer "em prejuízo das massas trabalhadoras organizadas e em proveito das empresas que controlam as inovações tecnológicas" (FURTADO, 1998, p. 29). O autor coloca que este processo de interdependência e globalização, traz de volta "o modelo do capitalismo original", visto na primeira revolução industrial, que se baseava nas exportações e no investimento estrangeiro.

Tendo este quadro em mente, Furtado faz uma reflexão sobre a realidade mundial emergente e assinala nove pontos distintos. Interessa, aqui destacar o quinto ponto:

5. Independentemente das mudanças na configuração da estrutura do poder político mundial, deve prosseguir a realocação de atividades produtivas provocada pelo impacto das novas técnicas de comunicação e tratamento da informação, o que tende a concentrar em áreas privilegiadas do mundo desenvolvido as atividades criativas, inovadoras ou simplesmente aquelas que são instrumentos de poder (FURTADO, 1998, p. 37)

O autor faz então um breve resumo sobre como se deu o processo de industrialização brasileiro, a partir dos anos 1930. Salienta que durante três séculos a economia brasileira baseou-se na exploração dos recursos, que em sua maioria eram considerados não-renováveis, florestas, minério de ferro e vários ciclos agrícolas. Cabe, aqui, lembrar que todo esse contexto foi aprofundado de forma sui generis, na célebre obra Formação Econômica do Brasil, publicada pela primeira vez em 1959. Dando sequência, coube ao Estado brasileiro papel central no processo de industrialização, baseado na substituição de importações, com imposição de altas tarifas alfandegárias. Porém, a partir dos anos 1970 o quadro internacional, antes favorável ao processo de industrialização, mudou graças principalmente a crise do dólar e ao primeiro choque do petróleo. Os países de terceiro mundo foram forçados a uma disciplina fiscal para quitarem suas dívidas externas. "Esses ajustamentos exigem um consenso e uma disciplina social difíceis de serem alcançados em qualquer país, e mais ainda em sociedades 
marcadas por profundas desigualdades e atraso político, como é a brasileira" (FURTADO, 1998, p. 40).

Com a abertura da economia, que se deu nos anos 1990, poderia se pensar como estratégia, aumentar o esforço para aprofundar a inserção internacional. Porém Furtado aponta que as altas taxas de crescimento que foram verificadas na economia brasileira entre os anos 1930 e 1970, foram devidas ao dinamismo do mercado interno. Ele, então, questiona “[...] cabe indagar se não terá sido um erro abandonar a estratégia de construção do mercado interno como "motor de crescimento" (1998, p. 40). E, reitera apresentando os dados de deterioração dos preços reais dos produtos primários que são exportados pelos países de terceiro mundo.

- A média desses preços no quinquênio 1986-1990 correspondeu, aproximadamente, à metade do que foram quarenta anos antes, ou seja, entre 1948-1955.

- Entre 1989 e 1991 os preços dos produtos primários exportados pelos países pobres declinaram em média $20 \%$.

- Estudo da comissão Sul pôs em evidência que os preços dos produtos manufaturados exportados pelos países do terceiro mundo cresceram $12 \%$ em termos nominais (em dólares), nos anos 1980. Ora, durante esse mesmo decênio, os preços das manufaturas exportadas pelos países industrializados cresceram $35 \%$.

- Se ajustarmos o poder de compra gerado pelas manufaturas exportadas pelos países do terceiro mundo, tendo em conta os preços das máquinas e dos equipamentos que eles importaram, vemos que a perda alcançou 32\% no referido decênio (FURTADO, 1998, p. 41-43).

É importante refletir sobre a dependência tecnológica, porque Furtado situa a mesma como um elemento essencial, haja vista que o próprio desenvolvimento tecnológico pode ser considerado dependente “[...] quando não se limita a introdução de novas técnicas, mas impõe a adoção de padrões de consumo sob a forma de novos produtos finais que correspondem a um grau de acumulação e de sofisticação técnica que só existem na sociedade em questão na forma de enclaves" (FURTADO, 1998, p. 48). Mas Furtado aponta também possibilidades para tentativas de superação do subdesenvolvimento para a segunda metade do século XX: um projeto de coletivização dos meios de produção, priorizar a satisfação das necessidades básicas da sociedade, admitindo que a solução para essa questão é de natureza política. A última estratégia apontada seria o ganho de autonomia nas relações externas assumindo papel de maior iniciativa comercial.

De toda a forma, a discussão sobre dependência tecnológica levantada por Furtado nos leva a refletir, por que, passadas duas décadas, o Brasil continua inserido na produção mundial 
como fornecedor de bens primários. O que se identifica atualmente é a transferência de tecnologia dos países centrais para os periféricos. A Industrialização parece inacabada. "Um forte indicador de que o processo não se completou é que a balança comercial latino-americana é estruturalmente deficitária em bens de maior intensidade tecnológica. Se houve avanços significativos na estrutura produtiva na fase da industrialização dirigida pelo Estado, estes não tiveram continuidade na fase seguinte" (FEIJÓ, 2011, p. 461). O que se evidencia é a periferia assimilando e reproduzindo o que é gerado pelos países ditos desenvolvidos.

\section{Breve histórico da balança comercial brasileira entre 2019 e 2020}

Buscamos, nessa seção, apontar brevemente, a partir de informações sobre as importações e exportações brasileiras, de 2019 até setembro de 2020, tendo como base dados disponibilizados no site do Ministério da Economia que, os apontamentos de mais de três décadas sobre dependência tecnológica e a produção de bens primários coadunam com o presente momento. O Brasil registrou, em 2019, uma balança comercial superavitária em US\$ 48 bilhões. As exportações brasileiras atingiram um total de US $\$ 225$ bilhões, o que representou uma queda de 5,8\% com relação ao total exportado em 2018. Já as importações chegaram ao valor de US\$ 177 bilhões, o que representou uma queda de 2,1\% com relação a 2018. O saldo da balança comercial brasileira nos últimos 10 anos foi positivo, exceto para 2014, ano em que o déficit chegou a US\$ 4,2 bilhões (MINISTÉRIO DA ECONOMIA, 2020).

O superávit comercial obviamente é recebido de forma positiva, mas quando olhamos mais atentamente para os principais produtos exportados pelo Brasil, a ordem é a seguinte: soja (12\% - US\$ 26,1 bilhões); óleos brutos de petróleo ou de minerais betuminosos, crus (11\% US\$ 24,2 bilhões); minério de ferro e seus concentrados (10\% - US\$ 22,7 bilhões); celulose (3,3\% - US\$ 7,5 bilhões); e milho não moído, exceto milho doce (3,2\% US\$ 7,3 bilhões) (MINISTÉRIO DA ECONOMIA, 2020). Essas 5 categorias de produtos citadas representaram $39,5 \%$ do total da exportação brasileira em 2019. Exceto a celulose, que faz parte da indústria de transformação, os demais itens pertencem ao setor agropecuário e indústria extrativista, demonstrando que o Brasil tem em sua pauta principal de exportação, produtos de baixa intensidade tecnológica, sendo, portanto, produtos com baixo valor agregado.

Verificando a pauta das importações brasileiras no ano de 2019, pode-se perceber que o principal item, representando 7,3\% do total, foram óleos combustíveis de petróleo ou de materiais betuminosos (exceto óleos brutos), cujo valor importado foi de US\$ 13 bilhões. Após, temos adubos ou fertilizantes químicos (exceto fertilizantes brutos) que representaram $5,1 \%$ do 
total, sendo que o valor importado foi de US\$ 9,1 bilhões. Em seguida, aparecem demais produtos da indústria de transformação $(4,5 \%)$ e equipamentos de telecomunicações incluindo peças e acessórios (4\%). A grande maioria se enquadrava como produtos da indústria de transformação (91\%) (MINISTÉRIO DA ECONOMIA, 2020).

Furtado (1986) chamou atenção para a tendência de elevação para o coeficiente de importação, sugerindo que na busca pela eliminação do subdesenvolvimento, novas técnicas são inseridas nos processos produtivos, criando uma inter-relação entre o setor agrícola e manufaturado, o que nas economias subdesenvolvidas não acontece de forma gradual e sim bruscamente. Quando analisadas, as importações brasileiras de óleos combustíveis de petróleo, adubos e fertilizantes químicos devem ser vistas considerando sob a perspectiva do comportamento do coeficiente de importações. Assim como, pelos dados acima, a importação dos produtos apontados pode não ser tão representativa, mas com efeito no nosso processo produtivo interno, portanto mais mecanizado. Com a utilização interna, cria maior "dependência" de produtos complementares.

O ano de 2020 está se constituindo um ano atípico, devido a pandemia da Covid-19. Essa crise de saúde pública transforma-se, também, em uma crise econômica, atingindo os países em sua totalidade. Quando verificado os dados de janeiro até setembro de 2020, percebese que o saldo da balança comercial continua positivo; e tudo indica que o superávit será maior que o obtido em 2019, pois o valor acumulado alcançou a cifra de US\$ 42 bilhões. Isso acontece pois, mesmo que o país esteja tendo uma diminuição das exportações com relação a 2019 de $7,7 \%$, às importações apresentaram queda ainda maior, sendo de $14,4 \%$ com relação ao mesmo período de 2019 (MINISTÉRIO DA ECONOMIA, 2020).

O maior reflexo na balança comercial ocorre com relação à indústria de transformação. O item desta pauta que teve maior queda nas exportações até o último mês registrado figurou em "demais produtos - Indústria de Transformação", representando 2,6\% do total das exportações brasileiras em 2020. A queda registrada foi de 47\%. Já a soja, principal produto da nossa pauta exportadora, apresentou um crescimento nas exportações de $27,8 \%$ em relação ao mesmo período do ano anterior (MINISTÉRIO DA ECONOMIA, 2020). O item de exportação que sugere maior uso de tecnologia reduziu em 47\%; todavia, a soja, que representou $17 \%$ das exportações até setembro de 2020 (US\$ 27,2 bilhões exportados) teve um aumento de quase $50 \%$.

Ainda em 2020, em segundo lugar apareceu o minério de ferro e seus concentrados (US\$ 17,3 bilhões - 11\%), produto que não teve oscilação. Em seguida, registrou-se o item de pauta óleos brutos de petróleo ou de minerais betuminosos, crus (9,8\% - US\$15,3 bilhões) que sofreu 
uma queda nas exportações de 13\% (MINISTÉRIO DA ECONOMIA, 2020). Também, registram-se produtos que tiveram aumento nas exportações em 2020 com relação ao mesmo período de 2019: açúcares $(63 \%)$, carne bovina $(25,4 \%)$, carne suína $(52,6 \%)$, ouro, não monetário (31,6\%) e algodão (36,1\%) (MINISTÉRIO DA ECONOMIA, 2020).

Em 2020, com o avanço do setor de agronegócios no Brasil, ocupam, o primeiro lugar na pauta de importações, adubos ou fertilizantes químicos (exceto fertilizantes brutos) sendo responsáveis por 5,1\% do total, o que gerou um valor importado de US\$ 5,8 bilhões. Em seguida, óleos combustíveis de petróleo ou de minerais betuminosos, com 4,9\% do total sendo que o valor FOB registrado foi de US\$ 5,8 bilhões. Após, têm-se as plataformas, embarcações e outras estruturas flutuantes, representando 4,8\% e o valor FOB expresso foi de US\$ 5,4 bilhões. Os demais produtos da indústria de transformação vêm em seguida, representando $4,5 \%$ do total importado, sendo que o valor FOB registrado foi de US\$ 5,2 bilhões. Ainda com um valor bastante alto, os equipamentos de telecomunicações, incluindo peças e acessórios, representando 4,2\% do total, sendo o valor FOB da ordem de US\$ 4,8 bilhões. No período de meses considerado do ano de 2020, a grande maioria dos produtos importados enquadra-se como produtos da indústria de transformação, de representatividade elevada na pauta dos produtos importados, 93\% do total (MINISTÉRIO DA ECONOMIA, 2020).

Nesses termos, o superávit na balança comercial mascara muitas vezes a deterioração nas trocas. Sem análises de maior profundidade, é possível apurar que o dólar apreciado pode trazer desajustes consideráveis para a balança comercial. Se, por um lado, tem-se os ganhos na valorização de bens primários exportados; por outro, as importações de produtos de transformação e outros que complementam a produção interna como óleos combustíveis ou fertilizantes ficam mais caros. Nossa dependência tecnológica alinhada à vulnerabilidade externa experimentadas atualmente, confirmam, ainda para os dias de hoje, os apontamentos de Celso Furtado sobre a produção e troca internacional quando afirma que "para um país subdesenvolvido, suas trocas externas são, acima de tudo, um intercâmbio de mercadorias produzidas a um nível técnico que lhe é acessível, por outras produzidas a um nível técnico que não lhe é acessível" (FURTADO, 1986, p. 233).

\section{Considerações finais}

Como mencionado no começo deste artigo, escrever sobre o pensamento furtadiano não é tarefa fácil, mas é reconfortante. Dizemos isso porque a atualidade nas obras de Furtado nos 
provoca, questiona, ao mesmo tempo nos instiga a buscar mudança. Como pensador nos legou um passado de muitas inquietações. Buscou compreender o Brasil desde sua essência, considerando os fenômenos históricos e estruturais. Tentou colocar em prática muitas das suas teorias, quando assumiu a direção da Sudene, implementando políticas públicas durante três governos, e assumindo cargo como ministro do planejamento, diga-se de passagem, foi o primeiro a ocupar o cargo.

Passadas mais de três décadas da publicação de Teoria e Política do Desenvolvimento Econômico (1986) as reflexões e indagações ainda são muitas. Por que ainda não superamos o subdesenvolvimento? Não somente o excedente agrícola como grande parte da produção brasileira de bens primários é exportada, mesmo assim os ganhos dessas produções não se revertem em melhorias das condições sociais da grande massa de trabalhadores rurais e urbanos no país. É inegável que se olharmos os dados sobre emprego e renda nas últimas décadas alguns avanços foram feitos, mas nada perto de superar as condições de nação subdesenvolvida.

Quanto a perspectiva ilusória no advento da "globalização" nutrida por muitos teóricos, principalmente dos liberais do mercado, já em 1998 na publicação de O Capitalismo Global, Furtado advertia para a concentração de poder que favorecia as grandes empresas e a da perda de comando provocada pela globalização. Sabemos por exemplo que o capital que hoje gere grande parte das empresas brasileiras não é nacional. Teria a abertura do mercado para o capital estrangeiro nos levado a uma fatídica desnacionalização? Se a resposta é sim, aumentamos então ainda mais a dependência.

Finalizando a breve reflexão que fizemos a partir do legado teórico disponibilizado nas publicações estudadas, se evidencia a atualidade do pensamento furtadiano para compreender, passado e presente da realidade brasileira. E sobre o futuro? Aí também encontramos em Celso Furtado pistas do que precisamos fazer, cientes de que parte da solução é de natureza política. E a outra parte deve permanecer nas análises criativas e propositivas das pesquisadoras e pesquisadores brasileiros; e é aqui, no pensamento latino-americano que encontraremos meios para galgar condições que nós, povo brasileiro, entendemos que precisam ser superadas.

\section{Referências}

BIESLCHOWSKY, R. Do "Manifesto latino-americano" de Raúl Prebisch aos dias de hoje: 70 anos de estruturalismo na CEPAL. Revista Economia Contemporânea, v. 24, n. 1, p. 1-25, 2020. 
CENTRO CELSO FURTADO. 1920-39 - Do sertão à capital. Disponível em: http://www.centrocelsofurtado.org.br/geral.php?ID_S=64. Acesso em 27 nov. 2020.

D'AGUIAR, R. F. Capítulo I - Celso Furtado - um retrato intelectual. In: SOUSA, C. M.; THEIS, I. M.; BARBOSA, J. L. A. (Org). Celso Furtado: a esperança militante: vol. I. [Livro Eletrônico]. Campina Grande: EDUEPB, 2020.

FEIJÓ, C. Desarrollo, vaivenes y desigualdad: una historia económica de América Latina desde la independencia In: Caderno do Desenvolvimento, Rio de Janeiro, v. 6, n. 9, p. 455-461, jul.dez. 2011.

FURTADO, C. O capitalismo global. São Paulo: Paz e Terra, 1998, 83 p.

Teoria e política do desenvolvimento econômico. 9a . ed., São Paulo: Nacional, 1986, 344 p.

MINISTÉRIO DA ECONOMIA. Brasil: informações gerais: Exportações, importações e balança comercial. Disponível em: http://comexstat.mdic.gov.br/pt/comex-vis. Acesso em 05 de nov. 2020.

OLIVEIRA, F. Crítica à razão dualista: o ornitorrinco. São Paulo: Boitempo, 2003, 150 p. 